\title{
Research on the Applications of Information and Internet Technology in the Ideological and Political Education of College Students
}

\author{
Jun $\mathrm{Wu}^{1}$ \\ ${ }^{1}$ Jiangxi University of Traditional Chinese \\ Medicine, \\ Nanchang,Jiangxi,330004 China
}

\author{
Quan Wen ${ }^{1}$ \\ 1Jiangxi University of Traditional Chinese \\ Medicine, \\ Nanchang,Jiangxi,330004 China
}

\author{
Yang Wan ${ }^{1,}$ a \\ ${ }^{1}$ Jiangxi University of Traditional Chinese Medicine, \\ Nanchang,Jiangxi,330004 China \\ a wanyangjxnc1977@126.com ( ${ }^{*}$ Corresponding Author)
}

\begin{abstract}
In this paper, we conduct research on the applications of information and Internet technology in the education of ideological and political for college students. Traditional ideological and moral education are controllable, because it is face-to-face communication between teachers and students, authenticity, also targeted, teachers can hate according to need several neck content, improve teaching quality, enhance teaching efficiency and teaching effect. University students' ideological and political education workers is the university student thought political education work network and the main behavior of the concrete operator, its quality directly associated with the effect of ideological and political education work under the network condition. We firmly believe that the information and Internet technology based methodology will be effective.
\end{abstract}

Keywords: Information and Internet; Ideological and Political; College Students.

\section{Introduction}

In today's age of the Internet, the network development in a day and it is convenience for people's work, study and life at the same time, ideological and political education of higher vocational colleges has brought impact, we can say that the network is a double-edged sword. Higher vocational students are the important Internet population, the Chinese Interne and the network has become an important tool to their learning and life. How to use the Internet to the ideological and political education in higher vocational colleges in the new position and avoid disadvantages, make excellent network culture in the service of the ideological and political education in higher vocational colleges, guide the students to recognize and resist the invasion of harmful network culture, this is an important subject in front of higher vocational colleges. Traditional ideological and moral education are controllable, because it is face-to-face communication between teachers and students, authenticity, also targeted, teachers can hate according to need several neck content, improve teaching quality, enhance teaching efficiency and teaching effect. The era of network virtual property, caused uncontrollable situation, this is a double-edged sword, for students and teachers in the school of information spread out, will lead to more students psychological problems and confusion on the rise, and hard to be solved, because compared with the traditional teaching model, students more ideological trend display is static, the identity of the reaction in the network environment, teacher is difficult to grasp which also make the teacher's teaching work more difficult [1-3].

Network ethics education mainly cover the following contents: first, carries on the scientific understanding of network education. Both must strengthen awareness of open education students, 
boldly pursued to make useful information on our advantage, and the essence of the cognitive network education their depth, duality, with scientific and reasonable use of network, avoid its negative effects. Improper hackers, that is, do not use email and web site, network attack others don't do harm to others, social and national interests; Not trusting and not weak, that is, keep sober mind, don't literally believe that echo even spread online ultra-reactionary speech; No infringement, namely not to implement online plagiarism others articles, reports, infringing activities such as the experimental data. Some college student online contingencies of civilization and the generation of unethical behavior will cause in the students themselves and mental patients. Ideological and political theory education which is a kind of concept of teaching practice, cultivate students expected sometimes refers to include is directly related to the curriculum, teaching method, leading system, the teaching object and other factors combined. The ideological and political theory courses as the main channel of ideological and political education. The ideological and political theory of network teaching platform is produced and developed under the age of the Internet [4].

In this paper, through review and theoretical survey, we conduct research on the applications of information and Internet technology in the education of ideological and political for college students. University students' ideological and political education workers is the university student thought political education work network and the main behavior of the concrete operator, its quality directly associated with the effect of ideological and political education work under the network condition. Therefore, to establish a high quality of university students' ideological education work team, it is urgent and significant. Specific measures are as follows: first, enhance the level of their political theory. Education workers must seriously study the basic principle, and consciously firmly in practice guided by the theory of socialism with Chinese characteristics, to grasp the stand, viewpoint and method. The second is to strengthen the network knowledge and skills of education workers the education and training. To make them understand the characteristics of the network culture and to promote effective use network to quickly access to information and evaluation of the ability and level of information. Three is to promote their positive innovation of ideological and political education methods. Ideological workers should adjust state of mind and leaned forward, adhere to the principle of democracy, affiliation and interaction. In the following sections we will discuss in detail.

\section{Our Proposed Methodology}

The Review of Information and Media Technology. The rapid development of new media, the carrier of the ideological and political education from oneness to diversity and three-dimensional, make the ideological and political education can be more convenient, more timely, more effective. In the era of new media, mobile phone text messages, blog, network BBS, etc. With its flexible and convenient features, make the ideological and political education work can be more convenient, can also be more varied in form, thus in the ideological and political education work can effectively integrate the old and new media in various education resources, can easily blend in the various content of ideological and political education among them. The traditional ideological and political education carrier due to on time synchronization requirements and the characteristics of the partiality in space, it is easy to make the students feel restricted and bound. In the Internet, for example, on the Internet, we can realize the unity of the text, sound, images, and animation, can be illustrated, audio and video and texts, which makes students such as immersive, make the traditional ideological and political education means the oneness of the diversification and three-dimensional, allowing students to see and hear more rich, more image and vivid. In the figure one, we illustrate the basic concept and pattern of technology based education pattern [5]. 


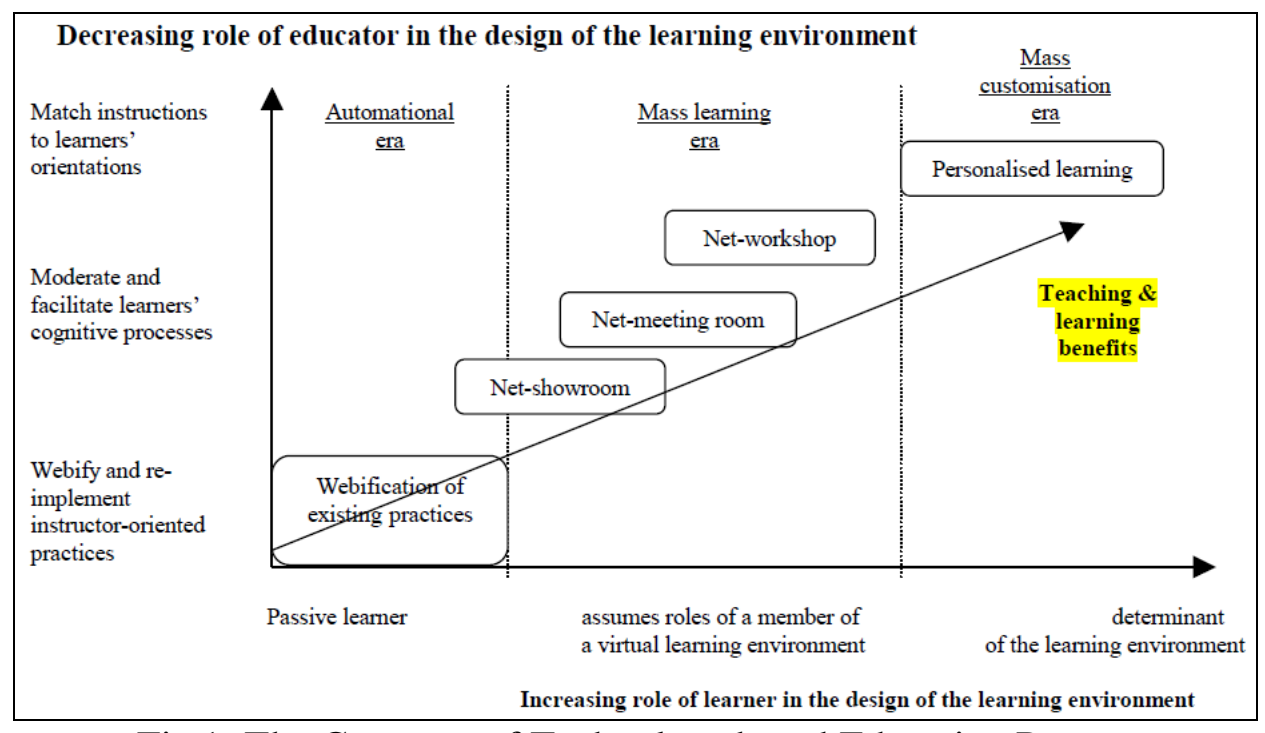

Fig 1. The Concepts of Technology based Education Pattern

The Education of Ideological and Political. Since the ideological and political education is the communication between the main body and the educators and the educated subject only through good communication and interaction, participation, to achieve the goal of ideological and political education, which requires communication between the main body which is based on the basis of mutual understanding and respect. But in the practice of ideological and political education, educators as disseminator of mainstream ideology, has the legitimate power, often at the above and dominant and manipulation of the ideological and political education communication content, communication, and communication environment selection and value judgment. Educators and the educated knowledge holds differences in the number and the information asymmetry between more to strengthen the absolute dominance of educators. To develop teaching and scientific research related to this course. In online learning misgivings, theory, expert interview, tutoring, academic salon classes two columns. Close to the actual student life, abstract to concrete and become boring for vivid which make it become college students information source, misgivings and navigation lights. In today's colleges and universities, nearly all the college students in Internet will through different ways of contact. Is the miracle of the Internet has made people, shortens the distance of time and space, make people between different languages, different levels and different environment of rapid communication to become a reality, the heart communication, situation for college students accommodation provides a golden opportunity. Students can refer to own hobby, interest in online selection, judgment, and integration of the information form their own political ideology, value judgment. However, the development and popularization of the Internet, it is easy to cause the students to western social way of life, economic ideas, political views from the appreciation to the convergence, so as to dilute the positive effect of ideological and political education, ideological and political education for college students to work put forward severe challenges.

At present, our country is in the period of social transformation. Tell from educator role itself, ideological and political education workers must set up the lofty communist ethics. Educators only have noble moral sentiment, to draw the general education object unity, around the individual guides them to the required direction toward the society. Into the network era, the knowledge revolution brought by the Internet and information explosion, often make educators bewildered. Social production organization excessive by highly centralized planned economy to socialist market 
economic model, development of social economic base by the single public ownership became with public ownership as the main body, the new pattern of multiple economic elements common development. In the great social change, the diversification of the economy, the people's political ideology has a strong impact. With the rapid development of Internet and wide application, more intensified the conflict between the political ideologies. In the figure two, we illustrate the traditional education model.

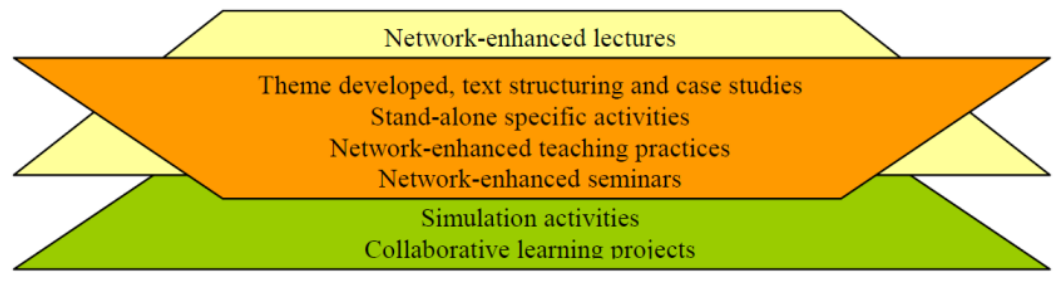

Fig 2. The Traditional Education Model

Teachers in the teaching process has been playing the role of authority. In traditional society, many of education resource are dependent on the teacher's authority. The source of teacher authority is that society gives, their knowledge and experience, and the characteristics of the students more authority center stage. On the one hand, the development of the network reconfiguration, the authority of education resources of low directly contributing to the education, make school teachers are no longer a rare resources, teacher's professional authority and legal authority, the authority and to inspire traditional authority gradually lost. Network development, on the other hand, the formation of the college students' activities of social and personal, network interaction to the development of college students provides a fair chance. The object choice more social activities performed by college students, and thus the subjectivity of the students to fully reveal, between teachers and students also division also born, formed a kind of new education relationship between democracy and equality. So, many young students are no longer easily accepts the ideological and political educators, dialogue and requirements to challenge their authority, make the work effect.

The Applications of Information and Internet Technology with Education. The Internet has the characteristics of multimedia communication, interactive and highly open, make the management difficulties, college should be in accordance with laws and regulations of national Internet management and formulate relevant system and strengthen the campus website and the unity of the network users to manage. Especially in college web site management. Provide new education carrier, rich ideological and political education. The development of mobile Internet and the widespread use of mobile devices, for ideological and political education in colleges and universities expand the new channels and means. Different terminologies have been used for online learning, a fact that makes it difficult to develop a generic definition. Terms that are commonly used include e-learning, Internet learning, distributed learning, networked learning, tele-learning, virtual learning, computer-assisted learning, Web-based learning, and distance learning. All of these terms imply that the learner is at a distance from the tutor or instructor, that the learner uses some form of technology. We can use Weibo, WeChat instant messaging software release to the student ideological and political theory, teaching information, mental health, quality development of all kinds of information, through content processing release to certain people to achieve a specific purpose of education. Mobile Internet system of this kind of rich resources, large information capacity, fast communication and strong interactivity, the advantages of wide coverage, and makes the ideological and political education in colleges and universities can be spread through new media actively correct ideas, 
theories and policies, which provide the new ideological and political education for college students education platform. We believe that the pattern will enhance the current model and methodology.

\section{Conclusion}

In this paper, we conduct research on the applications of information and Internet technology in the education of ideological and political for college students. The advantage of new media is to use it can carry out more direction and multi-dimensional communication between people and the rapid development of new media which greatly strengthened the social members, the connection degree of each group and each group asked. So the application of various media resources to ideological and political education work which can let the participation of the improved, can make the different groups of students can be implemented on the Internet and other new media on the sharing of resources. In the near future, we plan to do more theoretical analysis on the topic.

\section{References}

[1] Yu-long, S. (2014). Analysis of ideological and political education for college students in intelligent $3 \mathrm{~g}$ environment. Journal of Huainan Normal University.

[2] Qu, H. (2014). Study on the mechanism of involvement of working committee for next generation in ideological and political education of college students. Journal of Yunnan Open.

[3] Quan-heng, LA, et al. "Problems and Countermeasure in the Marine Culture Education for College Students." Journal of Hainan Radio \& Tv University (2014).

[4] Qing-hua R. The Application of " Micro" Carrier in the Ideological and Political Education for College Students-Taking Meizhouwan Vocational \& Technical College as an Example[J]. Journal of Anhui Vocational \& Technical College, 2014.

[5] Xiao-xue J, Department M, University C N. Ideological and Political Education of College Students under the New Exploration Network Conditions[J]. Journal of Cangzhou Normal University, 